\title{
Financial Problems of University Libraries
}

$D r . M c N e a l$ is director of libraries, University of Miami.

OONSIDERABLE CONCERN has been ex1 pressed in recent years over the ultimate destiny of the university and its research library. Too often, the two have been considered separately. Librarians are concerned about the growth in numbers of volumes, about problems of housing these growing collections, and about bibliographic control of such material. Increased acquisitions costs, increased cataloging costs, and the necessity for larger staffs have posed financial problems. These problems are inevitably an integral part of the university's total problem; through vastly increased research programs and expanding graduate programs, literature needs are increased and the production of literature in the form of reports, articles, and books is increased. This Malthusian spiral has thus far been met by libraries with almost no increase in the percentage required from the institutional budget for their operation.

As the university expands, it is logical that the library should grow. University building programs must recognize library housing needs. Some amelioration in this respect is offered by such innovations as the New England Depository and the Midwest Inter-Library Center but they still must be considered as experiments. Communications will probably be the determining factor in the ultimate failure or success of such developments. The faculty will be a vital factor in acceptance or rejection of such plans. Warehouse construction of the most inexpensive kind, with selective storage based on use of materials may be the most satisfactory solution eventually, especially in areas of isolation.

The educational objectives of the university properly determine the nature and growth of the university library. Changing concepts and normal growth of an institution should result in periodic redefinition of purposes, with a consequent effect on the library. Efforts at establishing an optimum size for the college library are valid only in terms of the program as it exists at a particular time. Any numerical limitation must be further qualified by provision for weeding the collection, and by definition of the curricula to be served. On the other hand, by its very nature the university is less susceptible to such limitation. Only through regional cooperation can some relief be found from the compulsion to provide everything for the scholar and research worker.

Few institutions are static. The process of evolution, from an undergraduate program leading to a Bachelor's degree, to a multiplicity of graduate programs and research respectability is a continuing process. The pressure on the library to provide for this growth has resulted in rapid increases in book collections, and concomitant with that increase, the need for more space and staff to properly house and service materials.

It is generally recognized that graduate 
work and research programs are an expensive part of a university in terms of instructional costs. It is also acknowledged that top-flight faculty for such programs require and demand proper library resources, often choosing or rejecting positions on that factor. It becomes imperative that the librarian anticipate new programs and possible areas of research interest, as well as continuing to support established programs.

Recently, some reaction has developed to the constantly increasing costs of library service to higher education. In particular, the Millett ${ }^{1}$ report has caused apprehension. One difficulty arises from the fact that too many librarians tend to read only that part of a work headed "Libraries." Others draw from the data interpretations which are partial and not complete out of context.

The table below serves to illustrate this point :
Such a negative approach, while statistically correct, provides ammunition for the guns already trained on us. It can be used without reference to the table in its entirety, and so used by detractors, would be a gross misrepresentation. It omits the obvious relationship between "Departmental instruction and research" and "Organized Research" - the former was $63 \%$ of the total in 1930 and declined to $45.1 \%$ in 1950 , the latter rose from $5.3 \%$ in 1930 to $14.2 \%$ in 1950. Millett recognizes the difficulty of differentiating between the two categories and refers to it as an accounting problem.

It may be noted that the factors showing the least fluctuation percentage-wise are "Administration and General" and "Libraries." Dollarwise, expenditures in the former were roughly five times as much in 1950 as in 1930 , and in the latter, almost six times as much. On the other hand,

TABLE I

Educational and General Expenditures, By Major Function²

\begin{tabular}{|c|c|c|c|c|c|c|}
\hline \multirow[b]{2}{*}{$\begin{array}{l}\text { TOTAL } \\
\text { Admin. \& Gen. } \\
\text { Dept. Instr. \& Res. } \\
\text { Extension } \\
\text { Org. Research } \\
\text { Libraries } \\
\text { Plant Opr. \& Maint. } \\
\text { Org. Act. Rel. to Instr. }\end{array}$} & \multicolumn{2}{|c|}{ I 930} & \multicolumn{2}{|c|}{ I 940} & \multicolumn{2}{|l|}{ I 950} \\
\hline & $\begin{array}{r}337, \text { I } 61,969 \\
40,089,036 \\
2 \text { I } 2,537,546 \\
\text { not reported } \\
\text { I } 7,988,524 \\
9,391,367 \\
57, \text { I } 55,496 \\
\text { not reported }\end{array}$ & $\begin{array}{l}\text { I00.0\% } \\
\text { I I.9 } \\
63.0 \\
\\
5.3 \\
2.8 \\
\text { I } 7.0\end{array}$ & $\begin{array}{r}482,258,996 \\
56,537,001 \\
255,930,644 \\
35,147,272 \\
26,989,744 \\
18,314,122 \\
62,887,563 \\
26,452,650\end{array}$ & $\begin{array}{l}100.0 \% \\
\text { I I.7 } \\
53.1 \\
7.3 \\
5.6 \\
3.8 \\
13.0 \\
5.5\end{array}$ & $\begin{array}{r}\text { I , 568, I } 89,098 \\
\text { I } 89,830,259 \\
707,632,003 \\
82,714,037 \\
222,232,588 \\
52,706,978 \\
200,964,498 \\
\text { I I } 2,108,735\end{array}$ & $\begin{array}{l}\text { I00.0\% } \\
\text { I } 2.1 \\
45.1 \\
5.3 \\
\text { I } 4.2 \\
3.4 \\
\text { I } 2.8 \\
7.1\end{array}$ \\
\hline
\end{tabular}

In a recent article in the Harvard Library Bulletin the table shown above is referred to as indicating "that library expenditures in the institutions studied amounted to four and one-half per cent of expenditures for instruction and research in 1930 , and that this figure had risen to nearly seven and one-half per cent by $1950 .{ }^{\prime \prime 3}$

1 Millett, Jolnn D. Financing Higher Education in the United States. New York, Columbia University Press, I 9.52.

3 Metcalf, Keyes D. "Financial Problems of University Libraries," Harvard Library Bulletin, 8:6, Winter. I954.
"Organized Research" cost more than I2 times as much. It should be recognized that the "Organized Research" figure as presented in this table does not take into consideration the income attached to it. In terms of contract research, higher education received $\$ 132,000,000$ from government sources in $1950 .{ }^{4}$

While libraries were the subject of criticism, and although admitting that library costs still claim only about $3 \%$ of the "edu-

+ Millett, op. cit., p. 353. 
cational and general" budget, it was stated: "It is safe to predict that library operating costs will grow as one of the important expense problems of both colleges and universities." 5

Yet in a later section on administrative costs we find for them a calm acceptance, based on the percentage figures of the above table, in these words ". . the relative share of total expenditures required for administrative and general purposes does not seem to have increased in any large degree during the decade of the I940's." 6

If we examine the treatment of the two areas, administration and libraries, there appears to be an inequity in the conclusions reached. It is entirely possible that we, as librarians, are responsible. Even since Fremont Rider cried "wolf" (and not without some justification) there has been a rising chorus of echoes, some from Harvard, some from Pennsylvania, and others from paronymous submarginal regions. Some of the data cited by Millett have a familiar ring. In our process of self-examination and critical evaluation it may well appear to an outside observer that there is "dissatisfaction with and confusion about the library services of higher education."7

Further ramifications of the problem of mounting library costs can be found in the increase in graduate degrees since the late I930's. U.S. Office of Education statistics show that earned degrees conferred by institutions of higher education in the U.S. in I $939-40$ were 3,290 at the Doctor's level and 26,73 I at the Master's and second professional level. In 1952-53, there were 8,309 Doctor's degrees and 6I,023 Master's and second professional degrees. ${ }^{8}$ This represents roughly an increase two and onehalf times in the graduate program.

5 Ibid., p. I $2^{\prime} 6$.

6 Ibid., p. I $6 \mathrm{I}$.

8 U. S. Office of Education, Circular No. 380 , Washington, D. C., Dec. I953.
The heavy increase in research programs in universities is an added pressure on library resources. Contract research has been largely in the area of physical and biological sciences. The acquistion of new materials and the securing of journals and academy literature in these fields represent an expensive outlay for those universities not having a strong emphasis in these fields over the years. Too frequently, research contracts have been accepted without regard to additional burdens placed on library resources. Actually, it is highly desirable that in accepting such contracts, library implications be considered, and where heavy use of existing resources or the addition of expensive materials is implicit, allocations be made from the overhead portion of the contract to the library. Such an agreement was effected, for example, between the director of libraries and the administration in $195 \mathrm{I}$ at the University of Tennessee.

Thus far, it has been attempted to give some indication of the problem from the standpoint of the librarian, with some refutation of criticism brought on by our own recognition of potential dangers. The problem still remains.

Competitive buying is one of our dangers. Despite cooperative efforts such as the Farmington Plan, which is not an abstaining or limiting agreement, the Midas-like counting and comparing of numerical and rarities strength continues. Yet so long as scholars pursue, refine, and advance knowledge, so long as educational institutions encourage research, there will be the demand for libraries to provicie the products of scholarship and research. In each university there will be the necessity for the administration to delimit areas of scholarly endeavor in terms of faculty and resources. Sooner or later the conclusion of interdependence, already recognized by librarians, must force itself upon the administration of competing in- 
stitutions. As Fussler put it " . . . libraries inevitably must not only become more selective in their acquisition policies than they are now; the libraries' parent institutions may also have to become increasingly critical of certain kinds of scholarship and of the geographical distribution of certain kinds of scholarship." Similar application of selectivity may well be made in deciding upon research contracts.

Recently, another cooperative effort has reached the organizational stage. Representatives of the University of Florida, Emory, University of Miami, University of Georgia, Florida State University, Georgia Institute of Technology and the Board of Control for Southern Regional Education gathered in Atlanta to discuss means of cooperation in research library development. At the initial meeting, upon the invitation of the Southern Regional Board, the president (or his representative) and the librarian of each institution were present. The discussion centered around the problems faced by institutions of higher education in the two states in providing libraries to serve expanding graduate programs. Cooperation in acquisition programs, maintenance of the existing Union Catalog in Atlanta, and possibilities of a regional center were among the issues discussed. The significant fact was that, in the presence of the presidents or their authorized representatives who participated, the strength of this program lies in that it is being initiated early in the development of these libraries, and may result in successful sharing of resources, which are needed but subject to infrequent use. Financial support of a central office with a paid executive secretary has been proposed and if accepted will insure continuing effort to realize the basic proposals.

\footnotetext{
- Fussler, Herman H. "Readjustments by the Li brarian." In Librarians, Scholars, and Bookscllers at Mid-Century, ed. by Pierce Butler. Chicago, University of Chicago Press, 1953 , p. 64.
}

Such regional approaches may not alter the library budget needs of the individual universities, but may well result in immediate increases in resources available, and provide for intelligent attacks on the substantial body of material not now available in the region.

The financial problem of the university library, then, is to continue to do with 3 to $4 \%$ of the institutional budget the job it has been doing with a like proportion since 1930. To realize that it is a problem, one need only to consult figures in Publishers' Weekly showing the increase in book costs, even over the last decade. Further evidence of the problem lies in statistics which show the increasing proportion of total library funds going into salaries and the consequent decrease in the proportion of funds available for books, periodicals and binding.

The possibly of developing a better ratio between expenditures for staff salaries and expenditures for books, periodicals and binding seems to warrant investigation. ACRL statistics for $1953-54$ indicate, in terms of the median, that the present ratio is one professional for each non-professional staff member. ${ }^{10}$ In many of the larger libraries, the ratio is two to one.

Actually the reverse should be true. One professional staff member should be able to supervise or direct two non-professionals. It seems likely that Columbia, with 95 professional and 225 non-professional staff and expenditures of $\$ 84 \mathrm{I}, 78 \mathrm{I}$ for staff salaries might point the way for many of the other larger institutions. Harvard, with $340 \frac{1}{2}$ staff members, has I $41 \frac{1}{2}$ professional and 199 non-professional with a salaries budget of $\$ 98 \mathrm{I}, 6 \mathrm{I} 5$. Illinois, with a total of $233 \frac{1}{2}$, has $131 \frac{3}{4}$ professional and $101 \frac{3}{4}$

(Continued on page 420)

10 COLLEGE AND RESFARCil LibRaRIES, I 5:71, January, I 954 . 
craft," he omits the fact that there would be a Uniterm card for longitudinal. He also overlooks the statement which we have made over and over again, to the effect that coordination is always carried out between two terms, and that the results of the first coordination are then carried over to a coordination with a third term, etc. The attempt to coordinate four terms at once indicates a lack of familiarity with the theory and practice of narrowing a search.

7) We have always recognized the burden of posting and have continued research on this subject. We have been able so far to describe partially ten different methods of posting. The best of these methods makes it possible to post a Uniterm index two or three times as rapidly as filing in a standard catalog, and we mean here total time and not unit time. We have published reports which indicate that Uniterm indexing reduces the time required for subject analysis of material from 200 to $300 \%$. Our methods of posting also reduce catalog maintenance by the same dramatic percentage.

8) $\mathrm{On}$ the matter of whether it is too early to release the system, we can only say that this is a decision made by the agencies for whom we work. Mr. Randall has based his judgment on 45 cards. We have already indexed over 20,000 documents using the Uniterm System. We have also published two Uniterm indexes in book form. It would seem that judgment on the Uniterm System or its practicality should be based on an example of more than 45 cards-Mortimer Taube, Documentation, Inc., Washington, D.C.

\section{Financial Problems of: University Libraries}

\section{(Continued from page 410)}

non-professional, at a cost of $\$ 814,368$. California (Berkeley) has $297 \frac{1}{2}$, of whom I 24 are professional and $173 \frac{1}{2}$ non-professional with a budget for salaries of $\$ \mathrm{I}, 079,386$.

The following tabulation lists some of the university libraries currently operating with approximately the staff relationship proposed in the preceding paragraph.

Such operations should provide a better distribution of duties, a more efficient operation, and greater economy. It may offer one way of getting more out of the salaries budget without lowering the percentage used for books, periodicals and binding.

In summary, it may be said that any approach to the financial problems of the university library should be made without apology for present demands on the university budget, since 1950 figures indicate only one-half of one per cent change from 1930.

The methods considered in this approach
TABLE II

\begin{tabular}{|c|c|c|c|}
\hline & Prof. & Non-Prof. & Total \\
\hline Brown & 22 & 36 & $5^{8}$ \\
\hline Cincinnati & 16 & 29 & 45 \\
\hline Columbia & 95 & 225 & 320 \\
\hline Fordham & 13 & $2 \mathrm{I}$ & 34 \\
\hline Iowa & $3 \circ \frac{1}{4}$ & 47 & $77^{\frac{1}{4}}$ \\
\hline Iowa State & 19 & 27 & 46 \\
\hline Massachusetts & 4 & 9 & I3 \\
\hline Miami & 19 & $34 \frac{1}{2}$ & $53 \frac{1}{2}$ \\
\hline Missouri & 26 & $36^{2}$ & 62 \\
\hline New York & 43 & II 6 & I 59 \\
\hline Pennsylvania & $55 \frac{1}{2}$ & $98 \frac{3}{4}$ & I $54 \frac{1}{4}$ \\
\hline Princeton & $47 \frac{3}{4}$ & 67 & I I $4 \frac{3}{4}$ \\
\hline Purdue & 23 & 30 & \\
\hline South Carolina & I $2 \frac{5}{6}$ & 21 & $33^{5}$ \\
\hline St. Louis & 15 & 20 & 35 \\
\hline Tennessee & 22 & 36 & 58 \\
\hline Utah & $20 \frac{2}{3}$ & 30 & $50 \frac{2}{3}$ \\
\hline Virginia & 29 & $39 \frac{1}{2}$ & $68 \frac{1}{2}$ \\
\hline Wayne & 22 & $38 \frac{1}{8}$ & $60 \frac{1}{8}$ \\
\hline
\end{tabular}

to the problem include the possibility of greater cooperation in acquisition and use of materials, the possibility of more funds from specific research contracts, and the possibility of more efficient use of staff. 